may be produced by a moderately bold sea front-a condition which is utilised commonly in the coastal navigation of the North Pacific-moderation of speed and careful soundings give practical security in most cases. Prof Barnes, of McGill University, has recently demonstrated the possibility of detecting the presence of icebergs near a ship by means of sensitive recording thermometers, and has exhibited automatically constructed diagrams which confirm the trustworthiness of his methods. The use of submarine bells in connection with lighthouses and lightships, and the fitting of microphonic receivers in Transatlantic passenger steamships and warships during the last eight or nine years, have also become common; and experience has proved this system to be of great value both for picking up lighthouses, lightships, and buoys, and for detecting the close approach of ships to one another in fog. On the whole, therefore, the openings for the additional apparatus suggested by Sir Hiram Maxim do not seem to be numerous or promising, nor is his statement of existing conditions complete. As matters stand, the officers of steamships have very onerous duties to perform, and unless additional apparatus is shown to be required in order to gain increased safety, it is not probable that shipowners or ship captains will favour its introduction, since that action would enlarge the labours of officers whose time and thought are already fully occupied in meeting grave responsibilities.

W. H. W.

\section{RESEARCHES AT THE VIENNA RADIUM INSTITUTE.}

THE Mitteilungen aus dem Institute für Radiumforschung, 12-17, deal with a variety of subjects of radio-active interest. Dr. Przibram describes a method for visualising and projecting on a screen the range of a-rays, depending upon the principle that a cloud of ammonium chloride fumes in an electric field rapidly clears when exposed to a-rays. The cloud is formed between the parallel plates of a condenser, at one end of which is the preparation giving a-rays. On applying a field of 200 volts between the plates the cloud in the vicinity of the preparation clears, leaving a perfectly sharp dividing line marking the extreme limit of the range of the a-rays.

Prof. Meyer and V. F. Hess discuss the heat effect of Hönigschmid's standard radium preparations, which they evaluate at ${ }_{3} 8$ calories per hour per gram of element, all three types of rays being completely absorbed, and numerous other data relating to these preparations. They include an interesting effect produced by one gram of radium after two years on a tube of fused quartz, which splintered and became quite rough on its inner surface, showing that this material is unsuitable for the storing of radium.

L. Flamm and H. Mache deal with the quantitative measurement of the radium emanation in a guard-ring plate condenser, with varying distances between the plates, and compare the values obtained with those calculated by various methods. Przibram also discusses the phosphorus content of the charged particles of phosphorus clouds. Of interest to the physiological chemist is a paper by Knaffl-Lenz and Wiechowski, calling in question the action of the radium emanation and of air exposed to a-rays in decomposing sodium mono-urate into easily soluble substances, and giving the negative results of many experiments.

Finally, a botanical paper on the sprouting of plants under the action of radium is contributed by Molisch, and is accompanied by plates which recall those illustrating the action of fertilisers. Shoots of Syringa vulgaris and Aesculus Hippocastanum are depicted showing those which have been subjected to the action of radium rays and of the radium emanation, and which, like Aaron's rod, have sprouted, while those not so treated have not. The action of the radium must not be overdone, or the plants are killed, and it is only of effect if applied during the rest period of winter in the end of November or in December. In addition to the varieties mentioned three others showed positive and four others negative results. Naturally the radium emanation, applied to the plant under a bell-jar, gives better and more pronounced results than the direct radiation. $F$. S.

\section{EXPERIMENTAL RESEARCH IN $A \ddot{E} R O N A U T I C S .{ }^{1}$}

Experiments on Airship Models.-During the past year further experiments have been made on the resistance of airship models, and on the forces and moments acting on inclined models of different forms. The resistance measurements included some tests of special shapes, made at the request of the superintendent of the Royal Aircraft Factory; and an investigation to determine the effect of bluntness of tail on the relative air flow and on the resistance. From visual observations and photographs of the flow past models in the small water channel, made with the aid of coloured streams, it was noted that the flow in the tail region even of an elongated model was very slow. It was inferred that truncation or modification of the tail within this "dead" region should have little effect on the head resistance. A model was accordingly made in which successive sections of the tail were removable, and it was found, as expected, that the effect of the removal of portions of the tail within the "dead" region was negligibly small. In the model tested, the full length of tail was about twice the maximum diameter, and it was found that a length of 0.8 of the diameter, from the tip, could be removed without appreciable effect on the head resistance. It follows, therefore, that within this region the tail may be rounded off or otherwise modified without loss of speed; a gain in lifting power is thereby secured, while the less pointed form presents advantages from the constructional point of view.

In addition to the model experiments above described, an interesting series of determinations of the head resistance of eight different airship forms was carried out at the Royal Aircraft Factory. These models were made of goldbeaters' skin, and were about $18 \mathrm{ft}$. in length, and $3 \mathrm{ft}$. in diameter. The method employed was to tow the models horizontally through the air at different velocities, the speed being maintained by means of a falling weight. The conclusions arrived at from these experiments were generally in accordance with those deduced from the mcasurements made on small models of the same forms in the water channel at the National Physical Laboratory. From the point of view of total balloon resistance alone, a fineness ratio, or ratio of length to maximum diameter, of $6 \frac{1}{2}$ to $I$ was found to be most efficient; but taking into account the other resistances in the completed airship, it was concluded that it might be desirable to reduce the fineness ratio to about $5 \frac{1}{4}$ to $I$.

The difficulties of obtaining results of high accuracy by the method of towing light models of this character through the air are very great, but nevertheless a comparison of the measurements of head resistance thus made on models of $3 \mathrm{ft}$. diameter, with those

1 From the Report of the Advisorv Committee for Aërnnautics for the Year 1911-12. (London: Wyman ard Sons, 1.td.) [Cd. 6249.] Price 2d. NO. 223 , VOL. 897 
given by tests in water of ebonite models of $\mathbf{I}$ in. diameter, is of much interest. The difference between the densities of the two media, air and water, is not a source of difficulty in such comparison: the relative resistances are directly proportional to the densities of the media, and allowance for the difference in density is thus readily made. According to the law of dynamical similarity, referred to in previous reports, and clearly enunciated by Lord Rayleigh in the report for I909-IO, the quantities on which variation in the resistance coefficient may be expected to depend are the relative dimensions, the relative velocities, and the "kinematical viscosities." The velocities in the two sets of experiments, made at the Aircraft Factory and the National Physical Laboratory respectively, were $20 \mathrm{ft}$. per second and $\mathrm{I}^{\circ} 78 \mathrm{ft}$. per second. The kinematical viscosities of air and water are in the ratio of $I_{3}$ to $I$. Employing the law of dynamical similarity the two series of experimental determinations enable a provisional estimate to be formed of the effect on the coefficient of head resistance of change in velocity, and of change in dimensions. Mr. Bairstow, of the National Physical Laboratory, has made the calculation, and employing the data so obtained, has estimated the resistance of a full-sized balloon, with smooth surface, of $40 \mathrm{ft}$. diameter and of specified form, with fineness ratio of $6: \mathrm{x}$, when travelling at the rate of 40 miles per hour, to be $320 \mathrm{lb}$. weight.

To obtain further information on this important question of the variation of the resistance coefficient with dimensions, a large wooden model of an airship, $6 \mathrm{ft}$. in length and $\mathrm{I} \mathrm{ft}$. in diameter, has been made at the laboratory, and its resistance will be determined by towing tests in the William Froude National Tank. These experiments are now in progress. A further model, 4 in. in diameter and $2 \mathrm{ft}$. long, is also under construction for towing tests in the tank, and it is hoped that a comparison of the various experimental results available may lead to valuable conclusions as to the relation between the resistance of models and of the full-scale machines, and may furnish data sufficient to enable the prediction, from observations on models, of the absolute magnitudes of the forces acting on full-sized airships and aëroplanes to be made with more confidence than is at present possible.

Investigation of the Pressure Distribution Round a Thin Plate and an Aërofoil.--The object of these experiments was to examine closely the character of the air flow round a thin plate or an aërofoil, and to investigate the way in which the total "lift" and "drift"-apart from friction-on the whole plate are built up from the pressures, or "suctions," at different regions of the upper and lower surfaces.

The detailed results and distribution curves, which will be given in the Technical Report, exhibit many points of interest, and of importance in aëroplane design. Thus for the aërofoil tested there was a particular angle at which the upper, convex surface gave its maximum contribution towards the total lift, and another, different angle at which the under, concave surface gave the maximum effect. It thus appeared to be a possibility that by variation of one of the surfaces improved efficiency could be obtained.

The nature of the pressure distribution on the convex surface of the aërofoil presents some remarkable features. At inclinations commonly occurring in flight practice, from $5^{\circ}$ to $10^{\circ}$, the negative pressure on the convex surface is a maximum, and reaches a very high value, at a point immediatelv behind the leading edge of the "plane." The same fact is shown in the distribution curves for different aërofoils at an angle of $6^{\circ}$ given by M. Eiffel, who has also carried out a large number of experiments in the plotting of pressure distribution, to which the National Physical NO. 2230 , vOL. 89]
Laboratory measurements may be regarded as complementary.

Another interesting feature of the results obtained for the aërofoil is that at an inclination of about $12 \frac{1}{2}^{\circ}$ there is a marked change in the pressure intensity on the convex surface, and from $12 \frac{1}{2}{ }^{\circ}$ to $20^{\circ}$ the conditions of flow appear to be so unsteady that no readings of the pressure intensity could be made, the pressure varying incessantly and erratically within wide limits. This critical region is also indicated, in a less marked manner, by the measurements made on the concave surface.

Effect of Separate Variation of the Upper and Lower Surfaces of an Aerrofoil.-In continuation of the investigation above described, into the pressure distribution, the effect has been examined of varying one surface only of the aërofoil, the curved under surface of the aforementioned aërofoil being replaced by a plane.

The general conclusion arrived at is that, as a first approximation, each of the surfaces of an aërofoil can be independently designed; the second approximation, due to interaction between one surface and the other, is sufficiently small to be regarded as of the nature of a correction.

The curves obtained for the lift and drift, and the ratio of lift to drift, show clearly the effect of replacing a cambered under surface by a plane one. Over the useful range of inclinations from $7^{\circ}$ to $12^{\circ}$, the ratio of lift to drift is nearly the same for both aërofoils, but the lift coefficient at $10^{\circ}$ decreases from $0^{\circ} 48$ to $0^{\circ} 42$. It follows from this that about I4 per cent. increase in wing area would be required to produce the same lift.

Effect of Variation of the Spacing of the Two Planes in a Biplane.-.These experiments were made with two facsimiles of a wing form of the Blériot type, and the "gap" between the two planes was varied from $0^{\circ} 4$ to $I^{\circ} 6$ times the breadth of either plane. The results were corrected for the resistance of connections. They show appreciable loss of lift per unit area as compared with the single plane; when the "gap " is equal to the breadth of either plane, the loss is I7 per cent. Even with a "gap" equal to I.6 times the breadth, the loss is still as much as ro per cent. The "drift" values for the biplane do not differ greatly from those for the single plane; the percentage losses in the ratio of lift to drift are thus nearly of the same magnitude as those in the lift.

The advantage that might be gained by employing a wider spacing than the usual one, with a gap equal to or slightly greater than the breadth of a plane, is, of course, to some extent, counterbalanced by the increased resistance and added weight due to the extra length of struts necessary. The best spacing depends on the conditions of design, and is different if the speed be required to be kept constant from that most suitable for a machine having wings of fixed area. For flight speeds ranging from 40 to 60 miles an hour the best biplane spacing is in the neighbourhood of that most commonly adopted, with a "gap" approximately equal to the chord.

Effect of Camber.-The effect of variation of the camber of the upper surface, and also of the lower surface, has been investigated. As already stated, it had been previously shown that, to a first approximation, the upper and lower surfaces might be independently designed. The experiments on the variation of camber of the upper surface were made on aërofoils having their lower surfaces nlane. The amount of camber of the upper surface giving a maximum value of the ratio of lift to drift was found to be about $I$ in 20. as compared with Eiffel's value of $I$ in 13.5 .

The experiments on the effect of varying the camber of the lower surface were made on an aërofoil in 
which the camber of the upper surface was about $I$ in Io. It was found that the ratios of lift to drift were practically unaltered by the change of camber in the lower surface, but the lift coefficient at a given angle of incidence increased steadily with increase of camber, the gain in lift amounting to about 17 per cent. for a lower surface camber of $x$ in 16 , as compared with a plane under surface.

Other Experiments in Connection with Aëroplanes. - Mr. O'Gorman has placed before the committee a considerable programme of further experimental work on aëroplane models, in relation to questions which have arisen in connection with constructional work proceeding at Farnborough. A scheme for further work has been approved by the committee, and this will be proceeded with as rapidly as circumstances permit. The committee held that the necessity of advancing more rapidly with these experiments rendered imperative the provision of another air channel; and, as already stated, it has been arranged to build a channel of section $6 \frac{1}{2} \mathrm{ft}$. square, for which provision will be made by the Treasury. The increased accuracy in measurement which it is hoped to attain by improved design in the reconstruction of the four-foot channel will also, if realised, appreciably increase the rate at which experimental data can be obtained.

Effect of Blade Area and Pitch on Propeller Efficiency.-At a constant translational speed, the departure from maximum efficiency is negligibly small over a fair range of blade widths, from about 34 to 4.8 in. The change of thrust under the same conditions is also small.

Tests have also been made on two series of propellers of different blade widths, in which the pitch was varied somewhat on either side of that obtaining in the original design. Some effects of increase in pitch may be inferred from these experiments; with the wider blades an improvement in efficiency was obtained with the increase in pitch, and in the experiments made the limit of improvement did not appear to have been reached. With the narrower blades the maximum efficiency obtained was for a ratio of pitch to diameter of about $0^{\circ} 80$. The investigation of the effect on the efficiency of variation in pitch will be continued.

Experimental Work on Full-sized Aëroplanes.-It was mentioned in last year's Report that arrangements had been made for conducting full-scale experiments. These were commenced early in IgI I under the direction of the superintendent of the Royal Aircraft Factory. The earlier work was directed to the determination of the effect of various modifications in an existing machine. An aëroplane of Farman type was available for the purpose, and the alterations made aimed at diminution of head resistance by various means; the increase of mechanical efficiency by improvement of propeller design and correct correlation of propeller and engine; improvement in the design of the wings; increased ease of control; and improved directional stability. In all these respects satisfactory results have been attained; the alterations have effected a marked improvement in ease of control, stability and speed, with increase of available lift. In connection with this work a standard form of "speed-resistance" and "speed-horse-power" curves has been adopted for setting out the qualities and performances of aëroplanes. This has been found very convenient for purposes of design.

Attention is also being given to the problem of obtaining during actual flight measurements of the principal quantities affecting the behaviour of the machine, a knowledge of which is necessary to enable the conditions of flight to be accurately analysed. Apparatus has been designed for recording the propeller thrust on machines in flight, and No. 2230 , vol. 89$]$ measurements are also being made of the relative wind velocity and the gliding angle, while the effect on the stability of modifications in design is being specially studied.

Meteorological Work.-In April, I9II, the Lords Commissioners of H.M. Treasury sanctioned the establishment, by arrangement with the War Office, of a branch of the Meteorological Office, in connection with the Royal Aircraft Factory, at South Farnborough, to supply meteorological information to those engaged in field work, and to carry on the investigation of the upper air for the Advisory Committee under the direction of the Meteorological Office. $\mathrm{Mr}$. J. S. Dines was appointed by the Meteorological Committee as meteorologist in charge of this branch office. Suitable accommodation for this experimental observatory was included in plans prepared for additional buildings at the Aircraft Factory.

This new branch of the Meteorological Office, for which accommodation is to be provided during I9I2, is designed to fulfil three functions:-

(I) To supply meteorological information and forecasts in a form directly applicable for the guidance of airmen.

(2) To carry on the experimental work for the Advisory Committee.

(3) To act as an observing station for the Meteorological Office.

Vertical Motion in the Air.-Experiments on vertical air currents have been carried out during the past year by means of balloons tethered to a point on a steel tower $95 \mathrm{ft}$. above the ground, with a view to the determination of the angular deviation from the horizontal of air currents at a moderate height. The method consists in following the motions of such a tethered balloon with a recording theodolite. The analysis of the records shows that the inclination of the wind direction to the horizontal does not normally exceed $20^{\circ}$, though on one occasion a downward current was observed making an angle of $43^{\circ}$ with the horizontal, corresponding in this instance with a vertical component of the wind velocity of about eight miles an hour. As a rule, the larger deviations from the horizontal were not met with on days of strong winds.

The Study of Gusts.-Some account was given in the previous report of the variation found in the gustiness of the wind at different levels. A comparison has been obtained during the past year of the gustiness at two points respectively 36 and $98 \mathrm{ft}$. above ground, the measurements being made by means of a pressure tube anemometer head. The gustiness at $36 \mathrm{ft}$. was found to be about 30 per cent. greater than that at $98 \mathrm{ft}$., for the site where the experiments were made.

In connection with the work on vertical motion, records of wind velocity were taken with a more open time scale than is usual, and these have given some further information of value with regard to gusts. In a gusty wind of normal type, a rise of wind velocity is usually followed almost immediately by a fall of approximately equal amount. In some of these observations, however, cases were found in which a sudden access of wind velocity persisted for at least one minute. Thus a case is recorded in which the wind rose suddenly from 13 to 23 miles per hour, followed by a slight fall and then a further rise to 28 miles per hour; the wind remaining above 20 miles per hour for more than one minute after the first rise. Attention is directed to this special type of velocity change on account of the probability that similar phenomena, though possibly of greater intensity, in the upper air currents may explain one of the types of conditions known to airmen as "holes in the air."

Experiments in progress on the wind towers give 
some valuable information as to the width of gusts, i.e. as to the lateral variation in the velocity of the wind. From observations taken at two points $40 \mathrm{ft}$. apart in a line approximately at right angles to the direction of the wind, the conclusion is drawn that the pressures due to the wind velocities at the same instant at two points $40 \mathrm{ft}$. apart may differ by as much as 50 per cent., and will frequently differ by 25 per cent. Differences of corresponding amount must, therefore, occur in the velocities of the natural wind striking the two wing tips of an aëroplane; thus, in a wind of ro miles an hour, for an aëroplane travelling at 50 miles an hour, the difference between the pressures at the wing tips might amount to io per cent. The observations were, for the most part, taken in strong winds of the order of 30 miles an hour, but the same proportionate variation has been found in lighter winds, though with diminution in the mean velocity of the wind the gusts become of less importance.

\section{UNIVERSITY AND EDUCATIONAL INTELLIGENCE.}

Cambridge.-At Emmanuel College a grant of $5 \mathrm{ol}$. a year for three years has been made to $\mathrm{Mr}$. C. E. Moss, in aid of his researches in connection with his forthcoming work on the British flora. From the Studentship Fund the following award has been made for research by graduates of the college :-a studentship of $120 l$. in stratigraphical geology to $\mathrm{Mr}$. R. D. Vernon.

The summer meeting is to be held from July 27 to August 20, and the principal subject of study will be "The British Empire"; other subjects will, however, also be dealt with. Among the lectures announced we notice the following:- "The Early Exploration of the Empire," H. Yule Oldham; "The Races of the Empire," Dr. E. A. Parkyn; "Australian Resources and Prospects," Sir George Reid; "New Zealand-its Historical, Scientific, and Educational Aspects," Prof. C. Chilton; "Our Frontier Neighbours in India," Col. Sir T. H. Holdich; "Nigeria, British Central Africa, and British East Africa and Uganda," Sir H. H. Johnston; "Universities of the Empire," Dr. A. Hill; "Eugenics and Genetics," Prof. R. C. Punnett, F.R.S.; "Principles of Aërial Flight," G. P. Bailey. In the education section there will be a practical course on "Elementary Experimental Science," by R. H. Adie.

Edinburgh.-Prof. Greenfield has resigned the holding of the chair of pathology. His resignation is to take effect from September 30 next.

LoNDON.-At an extraordinary meeting of the Senate held on July 17 , resolutions were adopted approving of the Foundling Hospital site in Bloomsbury for the proposed new headquarters for the Liniversity, in accordance with the recommendations contained in a report of the Special Sites Committee, over which Sir Philip Magnus, M.P., presides. Representations are to be made to the Government with the view of obtaining support for the scheme, and the Drapers' Company are to be asked whether they consider the site suitable for the proposed Senate House which they have offered to provide at an estimated cost of $60,000 l$. Lord Haldane is also to be asked to use his influence so that offers of financial support already made to him may be available for the Foundling Hospital site. A motion to refer back the report for further consideration was negatived by a small majority.

Mr. Otto Beit has been appointed a member of the governing body of the Imperial College of Science and NO. 2230 , VOL. 89$]$
Technology, in succession to the late Sir Julius Wernher, for the remainder of Sir J. Wernher's unexpired term of office, viz., four years from June I, I9II.

OXFORD.-A director of the Agricultural Economics Institute, which is being established by the University in conjunction with the Board of Agriculture and the Development Commission, is to be appointed by the Committee for Rural Economy in October next. Applications must reach the secretary, the School of Rural Economy, by September 30 .

Prof. W. M. Davis has resigned the professorship of geology in Harvard University. The chair will in future be filled by Prof. R. A. Daly, of the Massachusetts Institute of Technology.

Science announces that by the bequest of the late Dr. F. Bacon, Yale University will benefit by, probably, 500,000 dollars, of which 300,000 will go to the library and 200,000 to the Sheffield Scientific School, for the assistance of students.

Tine sum of $3000 l$. has been left to the University of Belfast by Mrs. F. Magrath for the foundation of a "Magrath clinical scholarship," to be given for proficiency in reports of bedside cases open to fourthyear medical students. The Vice-Chancellor, in announcing the legacy, said that it was certain to be of the utmost value in the medical school of the University. A further gift to the University is that of an equatorial telescope, the donor of which is $\mathrm{Mr}$. W. H. S. Monck.

\section{SOCIETIES AND ACADEMIES. LONDON.}

Physical Society, June 28.-Mr. A. Campbell, vicepresident, in the chair.-Prof. E. Wilson, B. C. Clayton, and A. E. Power: Hysteresis loss as affected by previous magnetic history. Hysteresis loss in iron at atmospheric and liquid air temperatures under three different conditions: (I) after the iron has been carefullv demagnetised; (2) after it has been subjected to a large force (previous history) of about 26 C.G.S. units; and (3) whilst it is under the influence of an external constant magnetising force after demagnetisation.--Prof. W. M. Thornton : Dielectric hrsteresis at low frequencies. An attempt to determine from dielectric hysteresis loops the nature of the change of polarisation which gives rise to the absorption of energy.-Prof. G. W. C. Howe and J. D. Peattie: The efficiency of generation of high-frequency oscillations by means of an induction coil and ordinary spark-gap. The apparatus used was similar to that employed in small radio-telegraph stations. A ro in. induction coil, operated from cells through a mercury interrupter, supplied power to an oscillatory circuit containing a spark-gap between spherical electrodes. Coupled to this circuit was another oscillatory circuit representing the aërial, and containing a variable resistance which constituted the high-frequency load. The input, output, and efficiency were determined for various degrees of coupling, various aërial decrements, different lengths of spark-gap and with various primary voltages, the object being to determine the effect of these various factors on the working of a small radio-telegraph station.-Dr. A. Griffiths and Miss C. H. Knowles: The resistance to the flow of water along a capillary soda-glass tube at low rates of shear.-S. W. J. Smith and J. Guild: The selfdemagnetisation of steel. The constituents, iron and iron carbide, are easily traceable in annealed steel. owing to the differences between their magnetic properties. The ferro-magnetic transition point of the carbide is about $500^{\circ} \mathrm{C}$. lower than that of the iron. 